\title{
Cross-linking of LFA-1 molecule enhances Fas mediated apoptosis of Jurkat and Burkitt lymphoma cell lines
}

\section{Dear Editor,}

Fas (Apo-1/CD95) is a type I cell surface receptor that mediates apoptotic death through activation by its natural ligand (FasL), or by agonistic anti-Fas monoclonal antibodies. Fas-mediated apoptosis has an important regulatory role in the immune system, involving thymocyte clonal deletion and tolerance acquisition, T-cell activation-induced cell death and immune response termination.

As many lymphoid and non-lymphoid malignant cells express Fas, this molecule may be important to mediate tumor cytotoxicity. ${ }^{1}$ However, although previous work shows that agonistic anti-Fas antibodies can kill mouse xenograft tumors, many different tumor types have now proven resistant to Fas-mediated apoptosis. ${ }^{2}$ The failure to conduct an apoptotic signal has been shown to be due to deletion, or down-regulation of Fas on cell membranes. ${ }^{1}$ It is also affected by expression of antagonistic soluble $\mathrm{Fas}^{1}$ and Fas-associated proteins, which interact negatively with Fas, e.g. Fas-associated phosphatase- $1(\mathrm{FAP}-1)^{3}$ and sentrin. ${ }^{4}$ It is furthermore affected by down-regulation of proteins involved in Fas-intracellular-signaling, e.g. caspase-8.

Research on how to render tumor cells sensitive to Fasmediated apoptosis is important and challenging. One possibility, which is currently being explored, is to interfere with the activity of adhesion molecules. It has recently been shown that inhibition of intercellular adhesion molecule-1 (ICAM-1/CD54), a member of the Ig superfamily, reduced the efficiency of membrane-associated Fas ligand so that its biological activity resembled soluble Fas ligand. ${ }^{5}$ In addition, cellular susceptibility to Fas-mediated apoptosis has been linked to actin cytoskeleton, which integrity is highly dependent on adhesion molecule interaction. ${ }^{6}$

Leukocyte function-associated antigen (LFA-1, or CD11a), a member of the B2-integrin family, interacts with ICAM-1 in a variety of cellular events, including Ag-specific $\mathrm{T}$ cell activation and leukocyte trans-endothelial migration. In this report we studied if LFA-1 participates in the regulation of Fas-mediated apoptosis in some tumor cell lines. We made the hypothesis that cross-linking LFA-I molecules would interfere with LFA-1/ICAM-1 interaction, thereby triggering FAS receptors and thus increasing the apoptotic rate.

To test this hypothesis we used Jurkat cell lines, as well as Epstein-Barr virus (EBV)-negative Burkitt lymphoma (BL) cell lines (BL 28, BL 41, DG 75), EBV-positive BL cell lines (Akata) and EBV-immortalized large lymphoma cell lines (Cherry and WW2). All cell lines were maintained in RPMI 1640 medium (Gibco BRL) supplemented with 10\% $(\mathrm{v} / \mathrm{v})$ fetal calf serum and antibiotics.

To test the sensitivity of the cell lines to Fas-induced apoptosis, $0.5 \times 10^{6}$ Jurkat and $\mathrm{BL}$ cells were treated with anti-Fas $\mathrm{CH}-11$ monoclonal antibody $(\mathrm{CH}-11 \mathrm{mAb})(\mathrm{MBL}$,
Japan) at concentrations of 125 and $500 \mathrm{ng} / \mathrm{ml}$. As control, cells were treated with equivalent concentrations of an unrelated IgM antibody. To measure the effect of anti-human LFA-I on Fas-induced apoptosis, Jurkat cells were preincubated for $4 \mathrm{~h}$ with anti-human LFA-I $(10 \mu \mathrm{g} /$ $\mathrm{ml}$, no. BCA1; R\&D Systems, UK). The cells were subsequently treated with 125 and $500 \mathrm{ng} / \mathrm{ml}$ of $\mathrm{CH}-11$ $\mathrm{mAb}$, respectively. After overnight incubation, the cells were stained with flourescein isothiocyanate (FITC)conjugated annexin V, using the Apoptest (Nexins Research, The Netherlands). The cells were washed with PBS, resuspended in the binding buffer containing annexin V-FITC at a concentration of $5 \mu \mathrm{g} / \mathrm{ml}$ and incubated for $15 \mathrm{~min}$ on ice. Fluorescence intensity of labeled samples was monitored with a FACScan flow cytometer (Becton Dickinson, San Jose, CA, USA) equipped with a $488 \mathrm{~nm}$ argon laser and analyzed using CellQuest software (Becton Dickinson, San Jose, CA, USA). All the experiments were made in duplicate. Data are presented as means \pm standard error of mean (S.E.M.).

When measuring the cellular effects of $\mathrm{CH}-11 \mathrm{mAb}$, in combination with anti-LFA-1, we observed a larger number of apoptotic cells (59 and $62 \%$, for 125 and $500 \mathrm{ng} / \mathrm{ml}$ of $\mathrm{CH}-11 \mathrm{mAb}$, respectively), compared to cells treated with $\mathrm{CH}-11 \mathrm{mAb}$ alone (25 and $37 \%$, for 125 and $500 \mathrm{ng} / \mathrm{ml}$ of $\mathrm{CH}-11 \mathrm{mAb}$, respectively) (Figure 1A). At the same time, anti-LFA-I had no apoptotic effect on Jurkat cells. The results suggest that the interaction between LFA-1 and its natural ligand, ICAM-1, may protect cells from Fasmediated apoptosis. Blocking of interaction consequently appears to enhance cell susceptibility to Fas-induced apoptosis. An alternative possibility is that the cross-linking of LFA-I interferes with certain steps in Fas-mediated apoptosis, e.g. the multimerization of receptors at the cell surface, processing of the apoptotic signal at the intracellular level or alterations of actin cytoskeleton.

In order to verify whether the obtained results could be related to expression of the adhesion molecules LFA-I and ICAM-I, we examined the expression of these molecules on Jurkat cells. $0.5 \times 10^{6}$ cells were washed with PBS and stained as follows: LFA detection was measured using anti-human LFA-1 $(1 \mu \mathrm{g} / \mathrm{ml})$, followed by R-phycoerythrin (RPE)-conjugated anti-mouse $\mathrm{mAb}(5 \mu \mathrm{g} / \mathrm{ml}$, DAKO). ICAM-1 detection was measured using RPE-conjugated anti-human ICAM-I $(2 \mu \mathrm{g} / \mathrm{ml}$, Becton Dickinson, San Jose, CA, USA). For all staining an appropriate antibody control was used. The mean fluorescense intensity (MFI) expression of the two adhesion molecules were 27 and 72 for LFA-I and ICAM-I, respectively; indicating that high expression of both molecules may indeed be responsible for protection from Fas-induced apoptosis. 
In order to study whether the sensitivity to Fas-mediated apoptosis increased in other tumor cell lines upon culturing
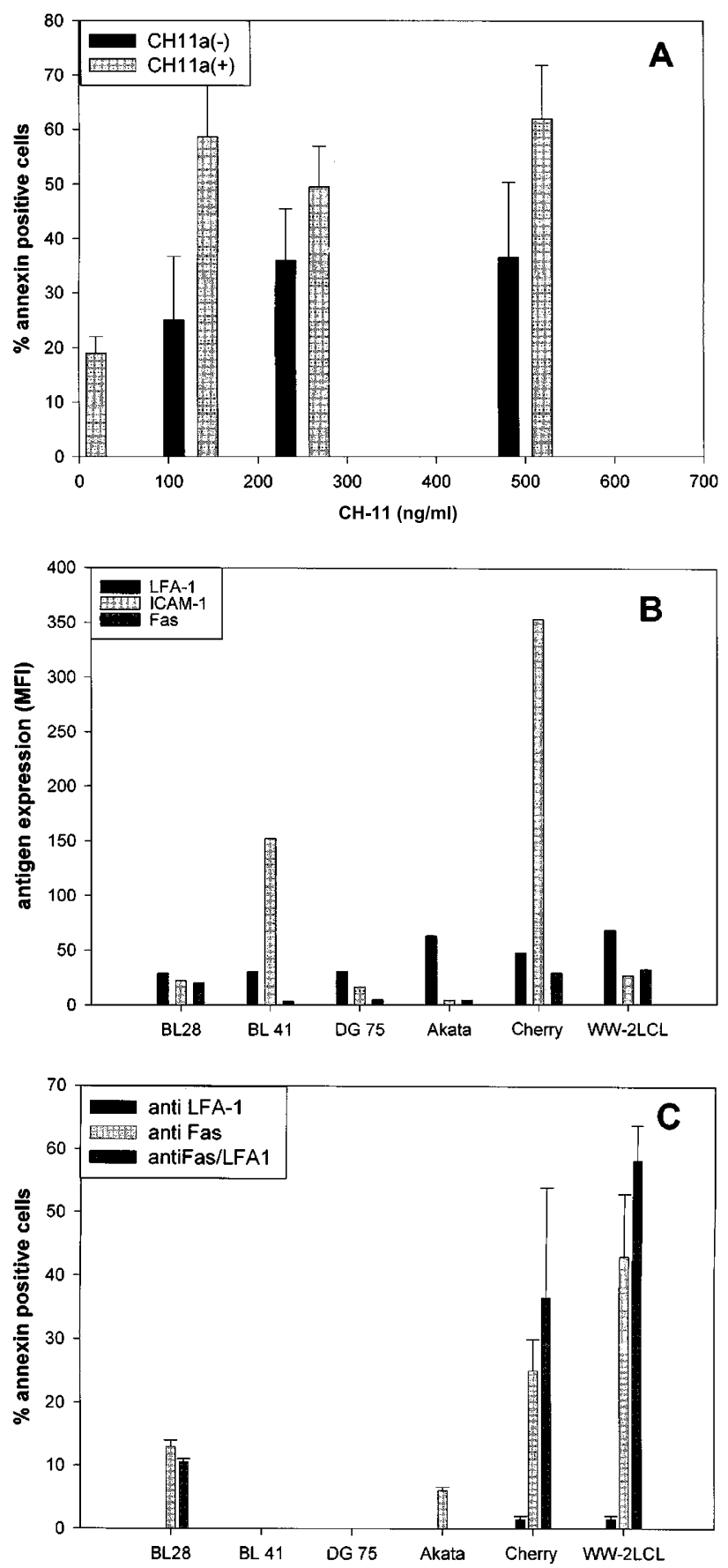

Figure 1 (A) Induction of apoptosis with $\mathrm{CH}-11 \mathrm{mAb}$ and the combination of $\mathrm{CH}-11 \mathrm{mAb}$ and anti LFA-I in Jurkat cells. The cells were preincubated for $4 \mathrm{~h}$ with anti-human LFA-1 at the concentration of $10 \mu \mathrm{g} / \mathrm{ml}$ and subsequently treated overnight with 125 and $500 \mathrm{ng} / \mathrm{ml}$ of $\mathrm{CH}-11 \mathrm{mAb}$ respectively. The following day, apoptosis was estimated using Apoptest as described in the text. Graph bars represent means+S.E.M. (B) Expression of ICAM-I, LFA-I and Fas in BL 28, BL41, DG 75, Akata, Cherry and WW-2LCL cells. The expression is shown as MFI (mean fluorescence intensity). (C) Percentage of apoptotic cells in cell lines treated with anti Fas $(\mathrm{CH}-11)$ and anti LFA-I monoclonals, or the combinations of the two reagents. Graph bars represent means + S.E.M. with anti-LFA-I, we studied a panel of Burkitt lymphoma cell lines. First, we measured the expression of LFA-I, ICAM-I and Fas on all cells (Figure 1B). We then measured their susceptibility to Fas-mediated apoptosis in the presence of $\mathrm{CH}-11 \mathrm{mAb}$ and anti-LFA-1, respectively. We also measured the effect of combining the two reagents (Figure 1C). The line DG75, that do not express Fas, was used as an internal control. Interestingly, in two of the lines (Cherry and WW2LCL), apoptosis induced by $\mathrm{CH}-11 \mathrm{mAb}$ (25 and $40 \%$ of annexin positive cells, respectively) correlated with high levels of Fas and adhesion molecules expression (46 and $67 \mathrm{MFI}$ for LFA-I and 353 and 26 for ICAM-I, respectively) (Figure $1 \mathrm{~B}$ ). In addition, the levels of apoptotic cells in BL28, Cherry and WW2LCL cultures increased when the combination of $\mathrm{CH}-11 \mathrm{mAb}$ and anti-LFA-I was applied to the cultures (14, 36 and $58 \%$, of annexin positive cells respectively), as compared to treatment with $\mathrm{CH}-11$ $\mathrm{mAb}$ alone (Figure $1 \mathrm{C}$ ). The remaining lines were insensitive to Fas-mediated apoptosis both in the presence of $\mathrm{CH}-11 \mathrm{mAb}$ reagent or when the combination of $\mathrm{CH}-11$ $\mathrm{mAb}$ and anti-LFA-I was added to the cultures.

It has recently been shown that cancer chemotherapy works through induction of apoptotic pathways. ${ }^{7}$ Although many types of cancer cells express Fas, few are constitutively susceptible to cell death triggered by it. Thus, in order to overcome the block of Fas-mediated apoptosis in cancer cells, it is necessary to identify and exploit additional signaling pathways interfering with Fas-mediated apoptosis. The pathway of interaction between adhesion molecules LFA-1 and ICAM-1, as shown by our results, may represent one such possibility. Further studies should be devoted to analyzing if LFA-I and ICAM-I interfere with the expression of caspase-8 or FLIP, whose ratio of expression was shown to be critical for Fas-susceptibility in Burkitt lymphoma cell lines. ${ }^{8-10}$

\section{Malgorzata Krzyzowska ${ }^{*, 1}$, Farideh Sabri ${ }^{2}$, Angelo De Milito ${ }^{2}$, Catharina Missailidis ${ }^{2}$, Ada Schollenberger ${ }^{1}$, Marek G Niemialtowski ${ }^{1}$ and Francesca Chiodi ${ }^{2}$ \\ 1 Division of Virology, Mycology and Immunology, Department of Infectious Diseases, Microbiology and Parasitology, Faculty of Veterinary Medicine, Warsaw Agricultural University, Grochowska 272, 03-849 Warsaw, Poland \\ 2 Microbiology and Tumor biology Center, Karolinska Institutet, Nobels vag 16, S 17177 Stockholm, Sweden \\ * Corresponding author: M Krzyzowska, Division of Virology, Mycology and Immunology, Department of Infectious Diseases, Microbiology and Parasitology, Faculty of Veterinary Medicine, Warsaw Agricultural University, Grochowska 272, 03-849 Warsaw, Poland}

1. O'Connel J et al. (1997) Mol. Med. 3: 294-300

2. Trauth BC et al. AMJ (1989) Science 245: 301-305

3. Mori S et al. (1996) Cancer Res. 56: 1874-1879

4. Okura T et al. (1996) J. Immunol. 157: 4277-4281

5. Sieg S et al. (1999) Cell. Immunol. 195: 89-95

6. Parlato $S$ et al. (2000) EMBO J. 19: 5123-5134

7. Fisher DE (1994) Cell 78: $539-543$

8. Kischkel FC et al. (1995) EMBO J. 14: 5579-5585

9. Baiocchi RA et al. (1997) Blood 90: 1737-1746

10. Tepper CG and Seldin MF (1999) Blood 94: 1727-1737 